\title{
CALCAR RECONSTRUCTION IN BIPOLAR HEMIARTHROPLASTY IN ELDERLY PATIENTS
}

\author{
Rahul Kadam¹, Abhishek Gupta², Abhay Chhallani ${ }^{3}$
}

${ }^{1}$ Associate Professor, Department of Orthopaedics, MGM Medical College, Navi Mumbai. 2Postgraduate Student, Department of Orthopaedics, MGM Medical College, Navi Mumbai. ${ }^{3}$ Lecturer, Department of Orthopaedics, MGM Medical College, Navi Mumbai.

\begin{abstract}
BACKGROUND

Intertrochanteric fractures are quite common in elderly patients by trivial trauma like falls due to weakness, muscle incoordination, poor vision, increased reaction time, etc. Intertrochanteric fractures can be broadly classified into stable and unstable types. Stable intertrochanteric fractures can be easily managed with satisfactory results, but the same cannot be done in unstable intertrochanteric fractures. The management of unstable intertrochanteric fractures is quite difficult due to unstable reduction of fracture and the stress of weight bearing. It is more difficult in elderly due to osteoporotic bone, poor bone quality, delayed healing, delayed mobilisation and poor compliance. There are many methods for operative management of intertrochanteric fractures mainly including DHS, PFN and hemiarthroplasty. This study will assess the functional outcome of cemented bipolar hemiarthroplasty with calcar reconstruction using head of femur as bone graft in unstable intertrochanteric fractures in elderly patients.
\end{abstract}

\section{AIM}

To evaluate the outcome of primary bipolar hemiarthroplasty with the calcar reconstruction for treatment of intertrochanteric fractures using Harris Hip Score.

\section{MATERIALS AND METHODS}

In this study, total 18 cases (Male 8 and Female 10) of intertrochanteric fractures were included. The mean age was 76.28 years (range 62 year - 91 year). All these patients were treated by cemented bipolar hemiarthroplasty and reconstruction of calcar was done by using same femur head as bone graft. Patients were followed up for a mean period of 6 months (range - 3 months to 9 months).

\section{RESULTS}

Bipolar hemiarthroplasty with calcar reconstruction for unstable osteoporotic intertrochanteric fractures allows early weight bearing and faster recovery with less risk of mechanical failure. The time to full weight bearing, the rate of post-operative complications and functional outcome was much better after cemented bipolar arthroplasty. Mean Harris Hip Score was 80.55 (Range 71-92).

\section{CONCLUSION}

Primary cemented bipolar hemiarthroplasty with restoration of abductor mechanism and calcar reconstruction by using same femur head as bone graft is a good surgical method in management of unstable intertrochanteric fractures in elderly patients, as it allows early ambulation, good functional outcome and stable hemiarthroplasty with less complications.

\section{KEYWORDS}

Bipolar Hemiarthroplasty, Calcar Reconstruction, Harris Hip Score, Intertrochanteric Fractures.

HOW TO CITE THIS ARTICLE: Kadam R, Gupta A, Chhallani A. Calcar reconstruction in bipolar hemiarthroplasty in elderly patients. J. Evolution Med. Dent. Sci. 2016;5(77):5701-5704, DOI: 10.14260/jemds/2016/1286

\section{BACKGROUND}

In elderly patients, although spine fracture is the most common fracture associated with osteoporosis, but hip fracture are the most common cause of morbidity and mortality in elderly patients. ${ }^{1}$ Almost ninety percent intertrochanteric fractures are due to a simple fall in elderly patients. ${ }^{2}$ The incidence of all hip fractures is almost 80 in $1,00,000$ persons of which intertrochanteric fractures are $45 \%$ of overall hip fractures. ${ }^{3}$ The tendency to fall increases

Financial or Other, Competing Interest: None.

Submission 10-08-2016, Peer Review 11-09-2016,

Acceptance 17-09-2016, Published 24-09-2016.

Corresponding Author:

Dr. Abhishek Gupta,

PG Hostel, MGM Medical College,

Kamothe, Navi Mumbai-410209.

E-mail: dr.abhishekguptaortho@gmail.com

DOI: $10.14260 /$ jemds $/ 2016 / 1286$

\section{(c) (1) $(9)$}

with patient age and is exacerbated by several factors including poor vision, decreased muscle power, blood pressure variation, delayed reflexes, muscle incoordination and other musculoskeletal problems. ${ }^{4}$ Most intertrochanteric fractures in elderly patients of age more than 65 years have reported mortality rates ranging from 15 to $30 \% .^{5}$ Evans made a classification of intertrochanteric fractures on the basis of the posteromedial cortex continuity and divides these fractures into stable and unstable types and determining the course of treatment. ${ }^{6}$ Stability of intertrochanteric fractures depends on the preservation of the posteromedial cortical buttress. ${ }^{7}$ Studies have revealed that bipolar hemiarthroplasty with early mobilisation in unstable intertrochanteric fractures in elderly have given good results. $8,9,10,11$ They are also associated with faster rehabilitation and earlier weight bearing. ${ }^{12}$ Before 1930, treatment of intertrochanteric fracture was mainly conservative, i.e. Russell's traction, skeletal traction, 
counterpoised suspension and well leg traction. The introduction of triflanged Smith-Petersen nail in year 1931 for fracture neck femur resulted in great improvement in union process and decreased mortality.

Johanssen in 1932 and West Cott in 1934 introduced a cannulated nail for hip. This had more accurate placement in the femoral head than the older nails. Austin T. Moore in 1934 treated intertrochanteric fractures with open reduction and internal fixation. Lawson Thornton in 1937 developed a plate that could be attached to the Smith-Petersen nail, which was known as the Thornton plate. This plate was a breakthrough invention in operative management of intertrochanteric fracture. Merwyn Evans in 1949 devised a method for classification of intertrochanteric fractures based on the continuity of posteromedial cortex into stable and unstable type. Evans had also suggested that internal fixation of intertrochanteric fracture has better chances of early mobilisation and causes reduced morbidity. ${ }^{4}$

The management options ranges from conservative managements to osteosynthesis by intramedullary and extramedullary implants. Replacement arthroplasty is also a good management option for treatment of intertrochanteric fracture. Despite of so many treatment options, the GOLD STANDARD or the most appropriate treatment for these fractures is controversial and there is no clear-cut best treatment method, specially for unstable intertrochanteric fractures. ${ }^{3}$

The main goal of treatment is stable fixation with early rehabilitation. Stable intertrochanteric fractures can be treated by osteosynthetic methods and these give satisfactory results. But the same result cannot be achieved in unstable intertrochanteric fractures when treated with osteosynthetic methods. Cut through of the screw, collapse and loss of fixation are common complications with conventional osteosynthesis.

An important issue while doing arthroplasty of hip in cases of intertrochanteric fractures is the decision to reconstruct the area of the calcar femorale, which is mostly broken in cases of unstable intertrochanteric fractures. ${ }^{13}$ This reconstruction is important for stability of the implant and helps in maintaining the length of the operated limb. ${ }^{14}$

This study will assess the functional outcome of cemented bipolar prosthesis with calcar reconstruction using the same femur head in unstable intertrochanteric fractures in elderly patients. The literature regarding this is sparse, especially with emphasis on the trochanteric and calcar reconstruction.

\section{MATERIALS AND METHODS}

This study was conducted in MGM Medical College, Navi Mumbai.

\section{Inclusion Criteria}

1. Patients associated with the comminuted intertrochanteric fractures.

2. Age more than 60 yrs.

3. Both males and females.

4. Co-operative for physiotherapy.

\section{Exclusion Criteria}

1. Stable IT fractures.

2. Age less than 60 yrs.

3. Patients unfit for surgery.

4. Open fractures.

5. Severely morbid patients.

\section{Pre-Operative Data}

Name of the patient, age and sex, fracture side, fracture type (Evans classification type) and mode of injury.

\section{Post-Operative Data}

Time to weight bearing, total hospitalisation days, complications, outcome assessment done with help of Harris hip score.

\section{Surgical Technique}

Patients were given spinal anaesthesia under all aseptic precautions. After induction patients were placed in lateral decubitus position and operating site scrubbed with betadine scrub, painting and draping done. The hip joint approached through anterior approach. Fractured head and neck were taken out without incising short external rotator muscles of the posterior side. Whenever there was a posteromedial deficiency involving the calcar was found, reconstruction of this region was done by a fashioned autologous bone graft harvested from the excised femoral head. For this, a piece of bone was cut from the femoral head. Its cartilage attachment was stripped off and was modelled into a block with help of an oscillating saw, bone cutter and bone nibbler. This block was carefully placed in the posteromedial region of the proximal femur to work as a support due to the absence of the original calcar. All other fragments of bone, the greater trochanter and the lesser trochanter were stabilised with SS wire after cementing of the femur stem of implant into femur canal. Extra cement was used to further stabilise the bone fragments held together by SS wire and final tightening of SS wire was done. Hip joint reduction done and the range of motion and stability of joint were checked after that. Drain placed leaving an appropriate tube length. Closure done in layers of joint capsule, iliotibial band, deep subcutaneous, superficial subcutaneous and skin.

\section{Postoperative Care}

Postoperatively, all patients were given same antibiotics cover as prophylaxis. All patients were given anticoagulation therapy with low-molecular-weight heparin and support stockings. Intravenous third-generation cephalosporin antibiotics were started on the day of surgery and the first dose was given one hour prior to surgery. Intravenous antibiotics were given till the third postoperative day. Postoperatively, the limb was kept in abduction using an abduction bar. Blood transfusions were given wherever required. Drains were removed after 48 hours of surgery and postoperative check X-rays were done. Patients were encouraged to sit and stand out of their bed twice daily from the first postoperative day and range of motion exercises started from the next day of surgery. Partial weight bearing was allowed from 2nd post-operative day onwards and the patient was mobilised with a walker. Stitches were removed on the 14th day of the surgery. The time required for each patient to start full weight bearing and also to reach their preoperative condition were recorded in terms of number of days. The functional outcome of surgery was assessed with Harris Hip Score postoperatively. 


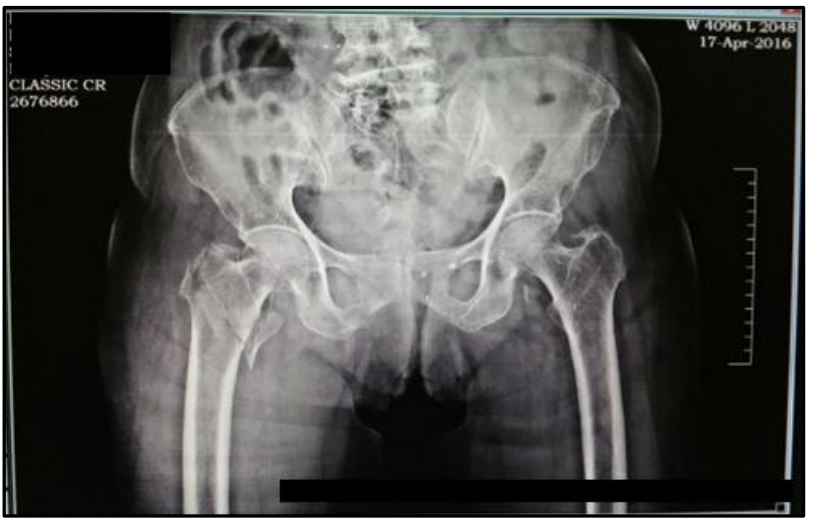

Fig. 1: Pre-Operative X-Ray

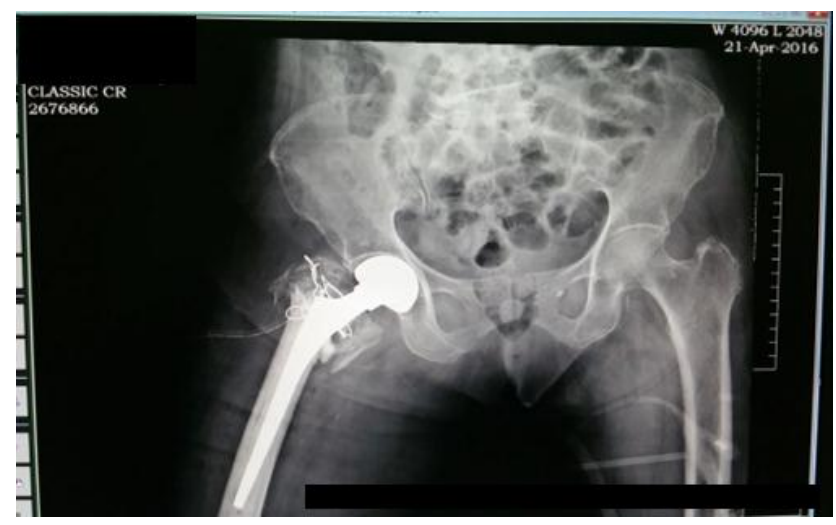

Fig. 2: Post-Operative X-Ray

\section{Intraoperative Pictures}

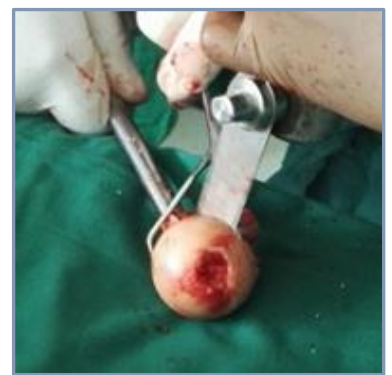

Fig. 3

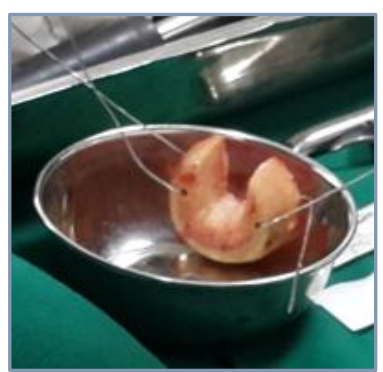

Fig. 5

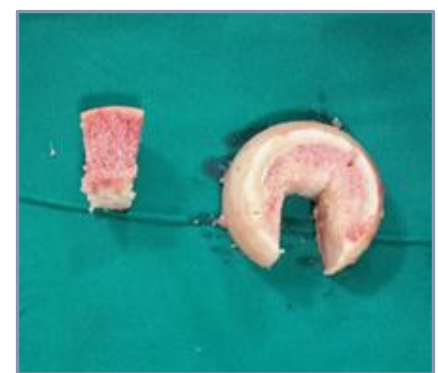

Fig. 4

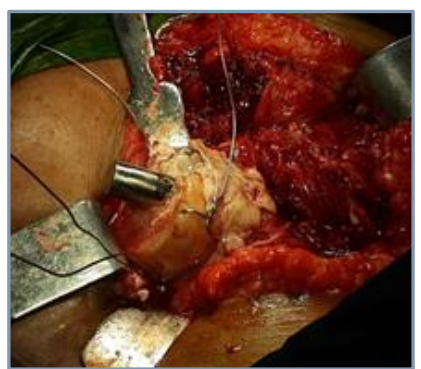

Fig. 6

\section{Follow-Up}

All patients were followed up at regular intervals. First two visits at 6 weeks and every 3 months after that. At each follow-up visit, examination was performed, and the patient was evaluated using the Harris Hip Score (HHS) and graded as $<70$ (poor), 70-79 (fair), 80-89 (good) and 90-100 (excellent). Antero-posterior radiographs of the hip were taken at each follow-up.

\begin{tabular}{|c|c|}
\hline Pain (Check One) & $\begin{array}{l}\text { Stairs } \\
\end{array}$ \\
\hline \multirow{2}{*}{$\begin{array}{l}\text { - None or ignores it (44) } \\
\text { - Slight, occasional, no compromise in activities (40) } \\
\text { - Mild pain, no effect on average activities, rarely moderate } \\
\text { pain with unusual activity; may take aspirin (30) }\end{array}$} & $\begin{array}{l}\text { - Normally without using a railing (4) } \\
\text { - Normally using a railing (2) } \\
\text { - In any manner (1) } \\
\text { - Unable to do stairs (0) }\end{array}$ \\
\hline & Put on Shoes and Socks \\
\hline \multirow{2}{*}{$\begin{array}{l}\text { - Moderate pain, tolerable but makes concession to pain. } \\
\text { Some limitation of ordinary activity or work. May require } \\
\text { Occasional pain medication stronger than aspirin (20) }\end{array}$} & $\begin{array}{l}\text { - With ease (4) } \\
\text { - With difficulty (2) } \\
\text { - Unable }(0)\end{array}$ \\
\hline & Absence of Deformity (All Yes $=4$; Less than $4=0$ ) \\
\hline $\begin{array}{l}\text { - Marked pain, serious limitation of activities (10) } \\
\text { - Totally disabled, crippled, pain in bed, bedridden (0) }\end{array}$ & $\begin{array}{l}\text { - Less than } 30^{\circ} \text { fixed flexion contracture [Yes] [No] } \\
\text { - Less than } 10^{\circ} \text { fixed abduction [Yes] [No] } \\
\text { - Less than } 10^{\circ} \text { fixed internal rotation in extension [Yes] [No] } \\
\text { - Limb length discrepancy less than } 3.2 \mathrm{~cm}[\text { Yes] [No] }\end{array}$ \\
\hline Limp & Range of Motion $(*$ indicates normal) \\
\hline $\begin{array}{l}\text { - None (11) } \\
\text { - Slight (8) } \\
\text { - Moderate (5) }\end{array}$ & \multirow{3}{*}{$\begin{array}{l}\text { - Flexion }\left(* 140^{\circ}\right) \\
\text { - Abduction }\left(* 40^{\circ}\right) \\
\text { - Adduction }\left(* 40^{\circ}\right) \\
\text { - External Rotation }\left(* 40^{\circ}\right) \\
\text { - Internal Rotation }\left(* 40^{\circ}\right) \\
\text { Range of Motion Scale } \\
211^{\circ}-300^{\circ}(5) 61^{\circ}-100(2) \\
161^{\circ}-210^{\circ}(4) 31^{\circ}-60^{\circ}(1) \\
101^{\circ}-160^{\circ}(3) 0^{\circ}-30^{\circ}(0) \\
\text { Range of Motion Score }\end{array}$} \\
\hline Support & \\
\hline $\begin{array}{l}\text { - None (11) } \\
\text { - Cane for long walks (7) } \\
\text { - Cane most of time (5) } \\
\text { - One crutch (3) } \\
\text { - Two canes (2) } \\
\text { - Two crutches or not able to walk (0) }\end{array}$ & \\
\hline Distance Walked & Sitting \\
\hline \multirow{3}{*}{$\begin{array}{l}\text { - Unlimited (11) } \\
\text { - Six blocks (8) } \\
\text { - Two or three blocks (5) } \\
\text { - Indoors only (2) } \\
\text { - Bed and chair only }(0)\end{array}$} & $\begin{array}{l}\text { - Comfortably in ordinary chair for one hour (5) } \\
\text { - On a high chair for } 30 \text { minutes (3) } \\
\text { - Unable to sit comfortably in any chair }(0)\end{array}$ \\
\hline & Enter public transportation \\
\hline & Yes (1) No (0) \\
\hline \multicolumn{2}{|c|}{ Total Harris Hip Score } \\
\hline
\end{tabular}




\section{RESULTS}

9 out of 18 patients had HARRIS HIP SCORE in range of 70 79,7 out of 18 patients had HARRIS HIP SCORE in range of 80 - 89, and 2 out of 18 patients had HARRIS HIP SCORE in range of $90-100$.

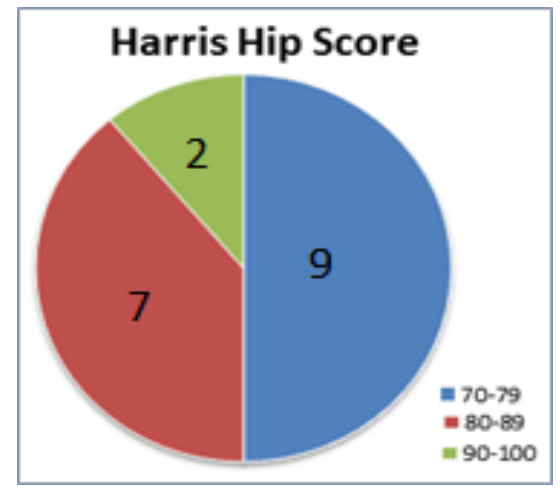

Fig. 7: Functional Evaluation with Harris Hip Score

\section{DISCUSSION}

The treatment of proximal femoral fractures in elderly patients with loss of calcar support requires different surgical method from that of other proximal femoral fractures. These fractures are better treated with primary cemented hemiarthroplasty with emphasis on the trochanteric and calcar reconstruction, so that a stable and mobile hip could be achieved with advantages of early ambulation and less hospital stay. Primary hemiarthroplasty with calcar replacement by using same femur head as bone graft is a good surgical treatment strategy for patients having intertrochanteric femur fracture with calcar loss, specially in elderly patients. The cemented hemiarthroplasty provides stable and mobile hip and early mobilisation of elderly patients. ${ }^{16}$ Also after cemented bipolar hemiarthroplasty, revision surgery is rarely required. The most important procedure is reconstruction of greater trochanter and calcar femorale in this surgery. It is required to maintain the stability of hip joint and to promote early ambulation. The outcome is a stable hip joint and which has a good range of motion without pain. Few patients had complications like superficial skin infection at suture line and delayed healing. These complications were acceptable as they do not affect the final outcome of the surgery.

\section{CONCLUSION}

Treatment of unstable intertrochanteric fractures is quite difficult. It is more difficult in patients where there is a calcar loss. In such cases, cemented bipolar hemiarthroplasty with calcar reconstruction by using same femur head as bone graft is a good treatment option. However, larger study with longer duration of follow-up is needed to establish usefulness of calcar reconstruction using same femur head as bone graft in cemented bipolar hemiarthroplasty.

\section{ACKNOWLEDGEMENT}

We would like to thank MGM Medical College and Hospital for allowing us to conduct this study. We would also like to thank Radiology Department, MGM Medical College and Hospital, for providing the required high quality X-Rays. We also thank the efficient OT staff of MGM Medical College and Hospital.
Lastly, we would like to thank the I.T. Department of MGM Medical College and Hospital for their constant support.

\section{REFERENCES}

1. Bandgar TR, Shah NS. High prevalence of vitamin D deficiency in Asian-Indian patients with fragility hip fracture: a pilot study. JAPI 2010;58.

2. Zuckerman JD. Hip fracture. New England Journal Of Medicine 1996;334(23):1519-25.

3. Moran CG, Wenn RT, Sikand M, et al. Early mortality after hip fracture: is delay before surgery important? J Bone Joint Surg Am 2005;87(3):483-9.

4. Koval KJ, Cantu RV. Intertrochanteric fractures. In: Bucholz RW, Heckman JD, Court-Brown CM, et al. eds. Rockwood \& Green's fractures in adults. $6^{\text {th }}$ edn. Philadelphia: Lippincott Williams \& Wilkins 2006:1794825.

5. Canale TS, Beaty JH. Fractures and dislocations of the hip. Campbell's operative orthopaedics. $11^{\text {th }}$ edn. Philadelphia: Mosby Elsevier 2007.

6. Evans EM. The treatment of trochanteric fractures of the femur. J Bone Joint Surg 1949;31B(2):190-203.

7. Kasser JR. Orthopaedic knowledge update 5 home study syllabus. Rosemont (IL): American Academy of Orthopaedic Surgeons 1996:217-32.

8. Haentjens P, Casteleyn PP, Opdecam P. Primary bipolar arthroplasty or total hip replacement for the treatment of unstable intertrochanteric and subtrochanteric fractures in elderly patients. Acta Orthop Belg 1994;60[Suppl 1]:124-8.

9. Sancheti KH, Sancheti PK, Patil S, et al. Primary hemiarthroplasty for unstable osteoporotic intertrochanteric fractures in the elderly: a retrospective case series. Indian J Orthop 2010;44(4):428-34.

10. Choy WS, Ahn JH, Ko JH, et al. Cementless bipolar hemiarthroplasty for unstable intertrochanteric fractures in elderly patients. Clinics in Orthopedic Surgery 2010;2(4):221-6.

11. Dai B, Xu JA, Lv JY. The treatment of elderly patients with intertrochanteric femoral fracture by cemented hip semi-arthroplasty. Journal of Clinical Orthopaedics 2007;5:25.

12. Haentjens P, Casteleyn PP, De Boeck H, et al. Treatment of unstable intertrochanteric and subtrochanteric fractures in elderly patients. Primary bipolar arthroplasty compared with internal fixation. J Bone Joint Surg Am 1989;71(8):1214-25.

13. Lin-Ge L, Jin-Xiang Y, Dong-Peng D, et al. Reconstruction of femoral calcar in artificial femoral head replacement for femoral intertrochanteric fractures patients. Clinical Journal of Medical Officers 2010;1.

14. El-Ghandour SM. Bipolar hemiarthroplasty with calcar substitution for unstable osteoporotic extra-capsular hip fractures. Egyptian Orthopedic Journal 2014,49(3): 202-8.

15. Harris WH. Harris hip score. J Bone Joint Surg Am 1969;51(4):737-55.

16. Salunkhe RM, Limaye S, Biswas SK, et al. Cemented hemiarthroplasty in proximal femoral fractures in elderly with severe osteoporosis: a case series. Med J DY Patil Univ 2012;5(1):36-42. 